\title{
Specific Physical Therapy Program for the Computer Programmers: A Case Report
}

\author{
Shahanawaz SD \\ Assistant Professor, Dr.D.Y.Patil College of \\ Physiotherapy, Dr.D.Y.Patil Vidyapeeth \\ (Deemed University), Pune, India
}

\author{
Tushar .J.Palekar \\ Professor and Principal, Dr.D.Y.Patil College of \\ Physiotherapy, Dr.D.Y.Patil Vidyapeeth \\ (Deemed University), Pune, India
}

\begin{abstract}
Objective: The purpose of this case report is to describe the specific physical therapy program for the computer programmers with low back pain.

Back ground of the study: Lumbar pain syndromes are best treated with a combination of approaches. Multimodal nonsurgical management of low back pain may include manual passive mobilization of joints and soft tissue, neuromuscular reactivation, exercise prescription, sensorimotor training, posture correction, movement or ergonomic re-education, and conditioning exercises. A comprehensive rehabilitation program should stress enhancement of motor patterns and functional tasks rather than focus on specific muscles (Standaert and Herring 2007).The management strategy should be dynamic in nature, meaning that it should alter according to changes in the patient's condition. The clinician should always avoid a Cook book mentality in the management and rehabilitation of the patient and so should design a strategy that meets the specific needs of each individual patient.
\end{abstract}

Case report: Vishal is a 49 years old computer programmer. He has a 06 years history of intermittent low back pain which was not allowing him to work or participate in any recreational activities. When he was trying to pick up any objects the pain was increased

Conclusion: The specific physical therapy exercises for computer programmer were used with duration for intervention: 5 days per week for 4 weeks shows improvement

Keywords: specific exercise, physical therapy, computer programmer, VAS ,lumbo-pelvic stability , neutral zone.

\section{Objective}

The purpose of this case report is to describe the specific physical therapy program for the computer programmers with low back pain.

\section{BACK GROUND OF THE STUDY}

Lumbar pain syndromes are best treated with a combination of approaches. Multimodal nonsurgical management of low back pain may include manual passive mobilization of joints and soft tissue, neuromuscular reactivation, exercise prescription, sensorimotor training, posture correction, movement or ergonomic re-education, and conditioning exercises. A comprehensive rehabilitation program should stress enhancement of motor patterns and functional tasks rather than focus on specific muscles (Standaert and Herring 2007). The management strategy should be dynamic in nature, meaning that it should alter according to changes in the patient's condition. The clinician should always avoid a Cook book mentality in the management and rehabilitation of the patient and so should design a strategy that meets the specific needs of each individual patient. Emphasis should be placed on patient education regarding the value of fitness and the safety of resuming activities. Appropriate patient education may prevent fear and avoidance and promote better coping strategies for pain management. When functioning normally, a muscle has optimum circulation and innervation, is able to move freely, is unimpaired in contracting and relaxing, and has normal elasticity and strength. All movements should be free of pain. Muscle function may depart from this norm in many ways, primarily because muscles are among the most susceptible of body structures. They must continually readjust to their use, disuse, or misuse.Muscle shortening frequently results. Stiff or shortened muscles are often activated in movements in which they otherwise would not take part. This overuse in turn leads to injury and/or to excess inhibition of their antagonists. In general, the shorter the muscle, the more it may inhibit its antagonists. Therefore, stimulating and strengthening a muscle's antagonists always aids treatment. 


\section{CASE REPORT}

Vishal is a 49 years old computer programmer. He has a 06 years history of intermittent low back pain which was not allowing him to work or participate in any recreational activities. When he was trying to pick up any objects the pain was increased. He felt sharp, stabbing pain in his low back low back and referred pain in his left buttock. And the symptoms were ease once he was taking rest for at least 3 to 4 days. Again when he come back to work, he spends most of the day sitting at the computer, he started to develop a constant deep pain varing from 4-7 on a pain visual analog scale of 10, it was aggravating after sitting more than 45 minutes ,bending to pick up items on the floor , and while dressing .on investigations MRI of the lumbar spine revealed disc desiccation with a 0.2 in. $(4 \mathrm{~mm})$ broad-based disc bulge. There was also mild to moderate canal stenosis with hypertrophic facet degenerative changes. On examination it was revealed that Asymmetrical hypertrophy of thoracolumbar Para spinals from T7 to L2, with increased muscle bulk on the right compared with the left, Limited trunk movements secondary to muscle guarding Increased lateral pelvic shift that is worse on left than right, trigger points was observed in left quadrates lumborum, left psoas major, bilateral adductor longus and left hamstrings

\section{DisCUSSION}

Mechanical loading is a major causative factor for backpain in computer programmers; however, the exact mechanical loading conditions (magnitude, frequency, duration, loading history, or some combinations) that cause back pain

Abnormal postures and positions may result in chronic nerve compression or may shorten muscles and, if the muscle crosses over a nerve, compression may occur. These postures may also contribute to muscle imbalance (Novak, J Orthop Sports Phys Ther, 2004) and should be avoided

A careful Analysis of muscle imbalance and its role in the perpetuation of the dysfunction. The muscular system lies at a functional crossroads since it is influenced by stimuli from both the CNS and the musculoskeletal systems. Muscles that tend to get weak often go hand in hand with muscles that tend to get tight. The traditional approach of strengthening a weak muscle entails progressive overload during exercise training in order to increase muscular strength, power, hypertrophy, and endurance. However, strengthening of a weak muscle in the presence of a tight or hypertonic muscle may be less than effective because the tight muscle is recruited first due to its lowered irritability threshold. Janda'a approach hypothesized that a weak muscle may merely be one that is inhibited because of a tight or hypertonic antagonist (Sherrington's law of reciprocal inhibition).

Several case studies have described treatment of patients with disk injury, LBP, and spondylolisthesis. ${ }^{1,3}$ Conservative management generally consists of a variety of manipulative and exercise methods, with initial activity modification and a graded increase in activity along with therapeutic exercises including low-impact aerobic conditioning and core stabilization. ${ }^{1,4,3}$ Outcome measures indicated that our physiotherapy treatment was appropriate.

In this study, we attempted to treat specific physical therapy programme for computer programmer. Consequently, pain in these patients may have been due to over loading and stress on back

\subsection{Treatment and Outcome Measure}

The pain scores were based on self-reporting values, assigned by patient on a 10 point pain intensity Visual Analog Scale (VAS), where $0=$ no pain and $10=$ worst possible pain.

Treatment aimed at improving core exercises, postural re-education, stretching, hamstring strengthening and also using the concept of neutral zone, ergonomic modification

Strengthening the transverses abdominus, multifidus, rectus abdominus, lattismuss dorsi, gluteus maximus which work for improving stability. To stretch the shortened muscles thus avoiding the postural asymmetry.

\section{RESUlt AND CONCLUSION}

The specific physical therapy exercises for computer programmer were used with duration for intervention: 5 days per week for 4 weeks. It was measured on VAS score where it was observed that pre score was 7 and post score after 4weeks was 3 .

The result of the author, serves to illustrate the effectiveness of lumbo-pelvic strength following with the concepts of neutral zone. 


\section{REFERENCES}

[1] Haun D.W., Kettner N.W. Spondylolysis and spondylolisthesis: a narrative review of etiology, diagnosis, and conservative management. J Chiropr Med. 2005;4(4):206-217.

[2] Earl J.E. Mechanical aetiology, recognition, and treatment in spondylolisthesis. Phys Ther in Sport. 2002; 3:79-87.

[3] Garry J., McShane J. Lumbar spondylolisthesis in adolescent athlete. J Fam Pract. 1998; 47(2):145-149. [PubMed]

[4] O'Sullivan P. Lumbar segmental instability. Clinical presentation and specific stabilizing exercise management. Man Ther. 2000;5(1):2-12.

[5] Smith J. Moving beyond the neutral spine: stabilizing the dancer with lumbar extension dysfunction. J Dance Med Sci. 2009;13(3):73-82

[6] Cresswell A., Thortensson A. Changes in intra-articular pressure, trunk muscle activation and force during isokinetic lifting and lowering. Eur J Appl Physiol. 1994; 68:315-321.

[7] Richardson C., Jull G., Hodges P., Hides J. Therapeutic exercise for spinal segmental stabilization in low back pain: scientific basic and clinical approach. Churchill Livingstone; Edimburg: 1999. p. 158

[8] Bonetti F., Curti S., Mattioli S., Mugnai R., Vanti C., Violante F. Effectiveness of a 'Global Postural Reeducation' program for persistent low back pain: a non-randomized controlled trial. BMC Musculoskelet Disord. 2010;16(11):285

[9] Dankaerts W., O'Sullivan P. The validity of O'Sullivan's classification system (CS) for a subgroup of NS-CLBP with motor control impairment (MCI): overview of a series of studies and review of the literature. Man Ther. 2011;16:9-14

[10] Janda, Vladimir, "Die Bedeutung der muskularen Fehlhaltung als pathogenetischer Fakt vertebra ngener Storungen," Arch. physikal. Therapie, 20 (1968), 113-116.

[11] Sherrington, C.S., "On plastic tonus and proprioceptive refl exes," Quart. J. Exp. Physiol., 2 (1909), 109-156.

[12] Kaltenborn, Freddy M. , Manual Therapy for the Extremity Joints, Oslo, Olaf Norlis Bokhandel, 1980.

[13] Cyriax, James, Textbook of Orthopedic Medicine, London, Hutchinson, 1969.

[14] Stoddard, Alan, Manual' of Osteopathic Technique, London, Hutchinson, 1980.

[15] Gunnari, Hans, and Evjenth, Olaf, Sequence Exercise, Oslo, Dreyers Forlag, Norwegian edition 1983, English edition 1984 (Chapter 7 on self-stretching)

[16] Evjenth, Olaf and Hamberg, Jern, Autostretching.The Complete Manual of Specific Stretching, Alfta Rehab Forlag, Alfta, Sweden, 1989

[17] Suni J, Rinne M, et al. (2006) Control of the lumbar neutral zone decreases low back pain and improves self-evaluated work ability: a 12-month randomized controlled study. Spine, 15;31(18):E611-20

[18] Novak CB (2004) Upper extremity work-related musculoskeletal disorders: a treatment perspective. J Orthop Sports Phys, 10:628-37

[19] Delisle A, Lariviere C, et al. (2006) Comparison of three computer workstations offering forearm support: impact on upper limb posture and muscle activation. Ergonomics,49(2):139-60 